\title{
Modelo Alternativo De Funcionamiento Del Sistema Turístico: Teoría De Enjambres Del Turismo Mundial
}

\author{
Manuel Antonio Abarca Zaquinaula (Lic. Tur.Msc.) \\ Universidad / Escuela Superior Politécnica de Chimborazo Extensión, \\ Norte Amazónica de la República del Ecuador
}

doi: 10.19044/esj.2017.v13n26p392 URL:http://dx.doi.org/10.19044/esj.2017.v13n26p392

\begin{abstract}
The present theory was developed based on the alternative model of operation of the tourist system proposed by the author (based on the models of Roberto Boullón, Neil Leiper, and OMT). It has to do,with a systemicmechanical approach with harmonious, coordinated, and routine functioning among its four parts (governing body of the tourist system, real-potential demand, geographic space, and tourist offer). Also, it obtains greater efficiency and profitability during the course of its operation. This theory explains that the tourist development of the planet must be based on the correct functioning of the tourist systems of the world. To improve the effectiveness of the management of the global tourism, it must be structured as follows; World tourism $=$ interconnection of tourist swarms, tourist swarms $=$ entanglement of two or more supra tourist systems, supra tourist systems $=$ link between two or more tourist molecules, tourist molecules $=$ union of two compatible tourist systems. A tourist system, therefore, can be formed in any of these destination: a canton, province, region, country, and any other destinations that do not necessarily have political limits. This study explains how tourist molecules, supra tourist systems, and tourist swarms are formed. It highlights the importance of understanding, at the first instance, the alternative model of operation of the tourist system. This is because in its compression lies the basis of the effectiveness and development of global tourism.
\end{abstract}

Keywords: Swarm, tourist corridor, molecule

\section{Resumen}

La presente teoría se desarrolló con base en el modelo alternativo de funcionamiento del sistema turístico propuesto por el autor (basado en los modelos de Roberto Boullón, Neil Leiper y la OMT), de enfoque sistémicomecánico con funcionamiento armónico, coordinado y rutinario entre sus 
cuatro partes (órgano rector del sistema turístico, demanda real-potencial, espacio geográfico y oferta turística) obteniendo mayor eficiencia $\mathrm{y}$ rentabilidad en su funcionar. Esta teoría explica que el desarrollo turístico del planeta debe basarse en el correcto funcionamiento de los sistemas turísticos del mundo y que para mejorar la efectividad del manejo del turismo mundial se debe estructurar de la siguiente manera; turismo mundial = interconección de enjambres turísticos, enjambres turísticos = entrelazamiento de dos o más supra sistemas turísticos, supra sistemas turísticos = enlace entre dos o más moléculas turísticas, moleculas turísticas = unión de dos sistemas turísticos compatibles. Teniendo presente que un sistema turístico puede ser formado en cualquier destino sea este: un cantón, provincia, región, país, entre otros destinos que no necesariamente tengan límites políticos. En el presente ensayo se explica cómo se forman las moléculas turísticas, supra sistemas turísticos y enjambres turísticos, resaltando la importancia de comprender en primera instancia, el modelo alternativo de funcionamiento del sistema turístico, ya que en su compresión radica la base de la efectividad y desarrollo del turismo mundial.

Palabras clave: Enjambre, corredor turístico, molécula

\section{Introducción}

Se denomina turismo a todas las actividades que realizan las personas durante los viajes y estancias en lugares distintos a su entorno habitual por un periodo de tiempo consecutivo inferior a un año y más de veinticuatro horas, con fines de: ocio, por negocios, salud, educación y otros. Los seres humanos desde sus orígenes se han visto impulsados a trasladarse a diferentes emplazamientos, por distintas razones, caza, religión, comercio, guerras, ocio etc (Sancho, 1998).

Estas actividades se realizan por todo el globo terrestre permitiendo viajar a millones de personas generando millones de divisas distribuidas en miles de destinos turísticos, a su vez, redistribuidas a miles de servidores, empresarios y/o microempresarios turísticos que conforman los muchos sistemas turísticos del mundo. Precisamente la preocupación del autor es que en muchos destinos turísticos su rentabilidad no es la óptima, afectando a las personas más vulnerables de una sociedad económicamente hablando, ya que al iniciar un emprendimiento en la zona de oferta turística de un destino experimentan la no presencia de las corrientes turísticas esperadas y se ven obligados a cerrar sus emprendimientos o a vivir modestamente apoyados de otras actividades económicas, esta mala experiencia la van transmitiendo a la ciudadanía en general formando un imaginario colectivo negativo acerca de los beneficios de la industria turística. 
En razón de análisis de la problemática antes mencionada se planteó un modelo alternativo de funcionamiento del sistema turístico (con base en los sistemas turísticos de Roberto Boullón, Neil Leiper y la OMT), con un enfoque sistémico-mecánico en el que se explica que cualquier destino turístico puede armar su sistema y gozar de sus beneficios, para efectivizar aún más esta propuesta se plantea la presente teoría de enjambres del turismo mundial, explicando que no se puede obtener la estructura del turismo mundial sin antes interconectar entre sí muchos ejambres turísticos, siendo estos el resultado del entrelazamiento de dos o más supra sistemas turísticos, estos a su vez estan compuestos del enlazamiento de dos o mas moléculas turísticas, y estas serán el resultado de la unión de dos sistemas turísticos compatibles entre sí, para mayor comprensión se explicará esta teoría en el desarrollo del presente ensayo.

\section{Metodología}

Antes de desarrollar el enfoque metodológico, es necesario establecer el significado de los términos que se están usando (enjambre, corredor turístico, molécula), de esta manera se pretende ser más efectivos (pertinentes) en el desarrollo de la metodología. Existen numerosas acepciones que pueden tomar los términos propuestos, las cuales dependen del área en que se aplique (medicina, ingeniería, gerencia, entre otros). Es conveniente partir de los conceptos generales y los aceptados en las experiencias desarrolladas sobre el tema de funcionamiento de sistemas.

Enjambre: es interesante citar el concepto de inteligencia de enjambres qué expresa que, corresponde a un grupo de técnicas que están basadas en el estudio del comportamiento colectivo en sistemas auto organizados y descentralizados (distribuidos). Estos sistemas están conformados típicamente por una población de agentes computacionales simples capaces de percibir y modificar su ambiente de manera local. Tal capacidad hace posible la comunicación entre los individuos, que detectan los cambios en el ambiente generado por el comportamiento de sus semejantes. Aunque normalmenteno hay una estructura centralizada de control que dictamina cómo los agentes deben comportarse, las interacciones locales entre los agentes usualmente llevan a la emergencia de un comportamiento global (Muñoz, 2008).

Corredor turístico: es un espacio homogéneo en el cual, por la cercana distancia de sus atractivos y servicios, llegan a una natural complementariedad. Por lo general se agrega que rutas troncales efectivizan su integración y la jerarquía de los atractivos y servicios determinan prioridades, y el rango de convocatoria de dicho espacio. Un mínimo de dos zonas turísticas dan origen a la creación de un corredor de esta característica.Vías de conexión entre las zonas, áreas, complejos, centros, 
conjuntos,atractivos turísticos, puertos de entrada del turismo receptivo y plazas emisoras del turismo interno que funciona como elemento estructurador del espacio turístico (Torrejón, 2004). Son las vías de conexión entre las zonas, las áreas, los complejos, los centros, los conjuntos, los atractivos turísticos, los puertos de entrada del turismo receptivo y las plazas emisoras del turismo interno, que funcionan como el elemento estructurador del espacio turístico. Según su función, pueden ser: corredores turísticos de translado y corredores turísticos de estadía (Boullón, 2006).

Molécula:es un arreglo tridimensional de átomos bien definido que posee movimiento translacional, rotacional y vibracional, no sólo importa el tipo y la cantidad de átomos que constituyen una molécula, también importa cómo éstos se distribuyen en el espacio, la estructura molecular tiene tres características que la definen: la constitución, la configuración y la conformación. La constitución señala la forma y secuencia de unión de los átomos, la configuración indica el arreglo espacial de los núcleos y la conformación precisa el número de arreglos espaciales posibles que resultan de la rotación de un grupo de átomos sobre un enlace sencillo (Cerro, 2009).

Para el desarrollo de la teoría de enjambres de la industria del turismo mundial, se empleó el enfoque sistémico-mecánico, con base en la propuesta alternativa de funcionamiento del sistema turístico de Manuel Abarca, empleando los siguientes métodos teóricos; método analítico, método lógico y método de la concreción.

\section{Modelo Alternativo de Funcionamiento del Sistema Turístico}

El presente modelo alternativo de funcionamiento del sistema turístico se lo realizó con base en los modelos de Roberto Boullón, Neil Leiper y la OMT, está compuesto de cuatro partes: órgano rector del sistema turístico, demanda real y potencial, espacio geográfico y la oferta del sistema turístico, que funcionando de una forma coordinada, armónica y rutinaria e interrelacionados entre sí, como una estructura real mecánica, que cada una de sus partes dependerá de la otra consecutivamente, obtienen un funcionamiento eficiente y aprovechan de manera sostenible los beneficios de la cadena de valor del gasto turístico (Abarca, 2017).

La fortaleza de este modelo alternativo de funcionamiento del sistema turístico radica en el entrelazamiento entre todos sus componentes proporcionando una estructura compacta y que todo su funcionar va a depender del entendimiento del nicho ecológico de la demanda turística, comprendiendo al nicho ecológico como "la posición relacional de una especie o población en un ecosistema o en el espacio concreto que ocupa en el ecosistema. En otras palabras, cuando hablamos de nicho ecológico, nos referimos a todas las actividades que realiza (ocupación), o la función que desempeña cierto individuo dentro de una comunidad" (Carabias \& Meave, 
2009). Teniendo presente que de la investigación y monitoreo constante del nicho ecológico de la demanda turística emergerán los gustos, preferencias, necesidades, exigencias y tendencias de las corrientes turísticas del destino, que sarán la luz y guía para el funcionar mecánico de las cuatro partes del sistema turístico, en especial de los servidores y/o empresarios del motor de la oferta turística, quienes tendrán que adaptarse, fortalecerse y moldearse a los gustos, preferencias, necesidades, exigencias y tendencias de su demanda para que mediante la competitividad empresarial, innovación turística y tecnológica puedan satisfacer a plenitud a la demanda turística del sistema. Recordando que la competitividad empresarial es "la innovación en su sentido más amplio, que comprende tanto nuevas tecnologías como nuevos modos de hacer las cosas" (Porter, 2003). Además cabe resaltar que este modelo alternativo de funcionamiento del sistema turístico sugiere no crear empresas y/o emprendimientos turísticos, inversión económica, de talento humano y/o estrategias de desarrollo turístico desde la oferta, si no desde los gustos, preferencias, necesidades, exigencias y tendencias de la demanda turística del sistema.

Cabe resaltar que este sistema turístico va ha ser la unidad base con la que se planteará la teoría de enjambres de la industria del turismo mundial, significando qué, el funcionamiento de cada componente que integren los enjambres, será igual al funcionamiento del sistema turístico en mención.

Gráfico 1. Modelo alternativo de funcionamiento del sistema turístico

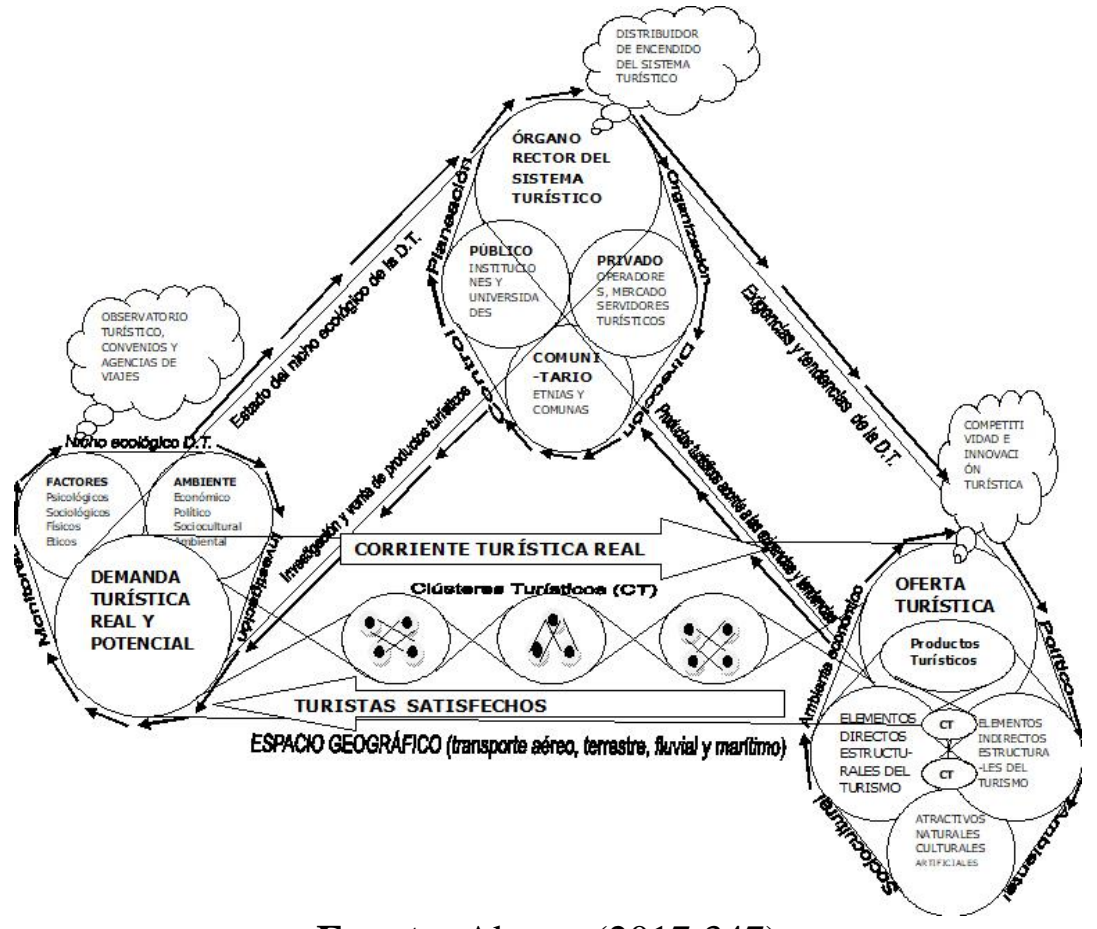

Fuente: Abarca (2017:347) 


\section{Resultados y Discusión}

La presente teoría nace del interés de efectivizar el manejo del turismo mundial y su correcto desarrollo sostenible, para ello se plantea la posibilidad de unir, enlazar, e interconectar muchos sistemas o destinos turísticos que sean compatibles entre sí, con base en los gustos, preferencias, necesidades, exigencias y tendencias de sus demandas turísticas, a través de enlaces turísticos que permitan armonizar el funcionamiento y desarrollo sostenible del turismo mundial, proponiendo así; unir dos sistemas o destinos turísticos compatibles entre sí que daran lugar a una molécula turística, el enlazamiento de dos o más moléculas turísticas = un supra sistema turístico, el entrelazamiento de dos o más supra sistemas turísticos darán lugar a un enjambre turístico y la interconexión entre dos o más enjambres turísticos conformarán la estructura del turismo mundial. La compatibilidad de los sistemas turísticos va a estar dada por el análisis de los gustos, preferencias, necesidades, exigencias y tendencias de sus demandas turísticas qué se unirán, enlazaran e interconectarán para satisfacer a plenitud sus necesidades de transporte, recreación, ocio, hospedaje, alimentación y bienestar. Para mayor comprensión se describen a continuación.

\section{Molécula Turística}

La molécula turística es el resultado de la unión de dos sistemas turísticos compatibles entre sí (con gustos, preferencias, necesidades, exigencias y tendencias similares entre sus demandas) uniéndose para fortalecer su competitividad empresarial, innovación turística y tecnológica que les permita satisfacer a plenitud las demandas de sus corrientes turísticas, comprendiendo que, esta unión tendrá que darse en términos de mejorar el aprovechamiento sostenible del gasto de las corrientes turísticas reales de los dos sistemas, a través de la fusión de sus órganos rectores, creando un nuevo órgano rector molecular, que a su vez permitirá la creación de dos corredores y variedad de productos y/o servicios turísticos conjuntos.

Cómo se puede apreciar en el gráfico 2, al momento del enlazamiento de los sistemas turísticos, los órganos rectores de los dos sistemas se van a fusionar transformándose en el órgano rector de la molécula turística. Éste órgano va a estar conformado por los representantes de los sectores: público, privado y comunitario de los dos sistemas y de los dos corredores turísticos que se crearán al momento de la fusión.

El órgano rector de la molécula turística, tendrá las funciones de planeación, organización, dirección y control de los dos sistemas y dos corredores turísticos. De la misma forma que en el modelo alternativo de funcionamiento del sistema turístico tendrá que investigar y monitorear el nicho ecológico de la demanda real y potencial de la molécula (gustos, preferencias, necesidades, exigencias y tendencias), ya que esta información 
le permitirá incidir a través de las herramientas del marketing en la toma de decisión de viaje de sus corrientes turísticas potenciales, asegurando suficiente combustible (corrientes turísticas reales) para los dos motores de las dos ofertas de la molécula turística.

Gráfico 2. Unión de dos sistemas, formando la molécula turística

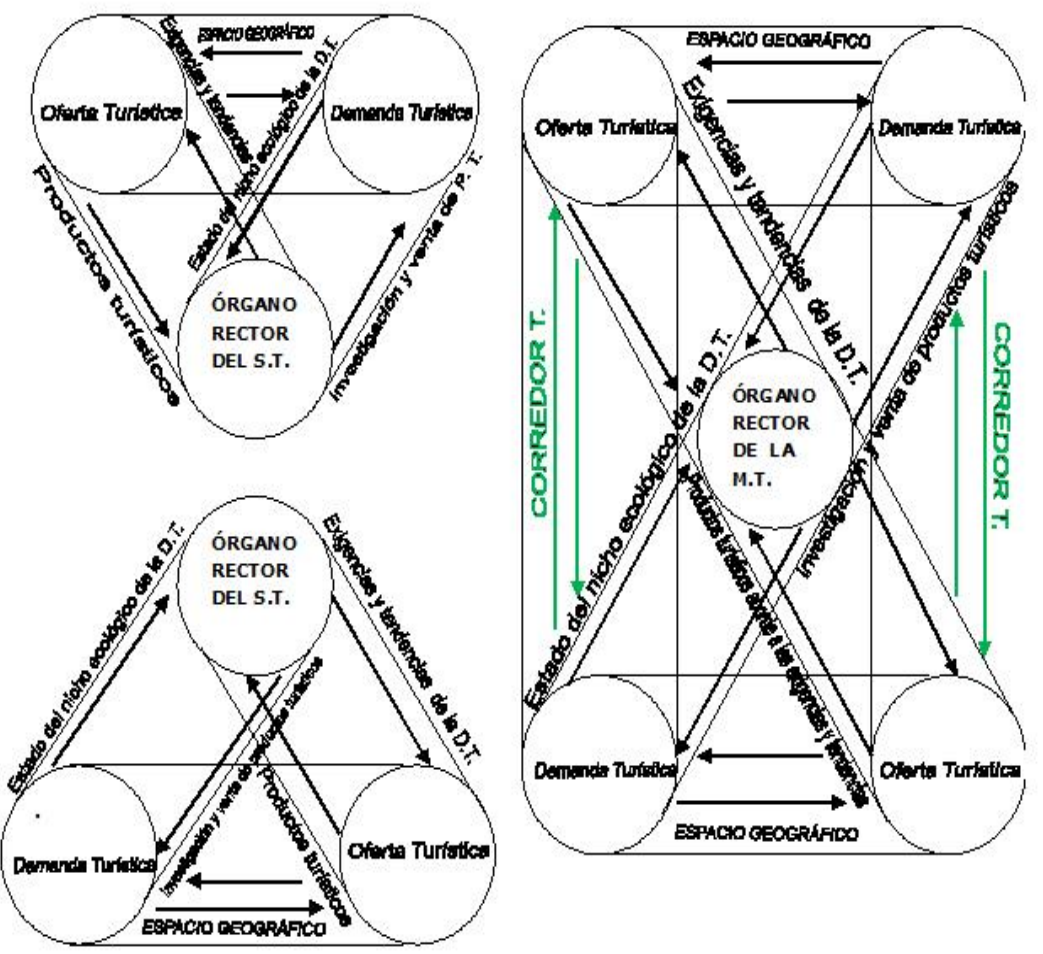

Fuente: Elaboración propia

La oferta turística de la molécula está formada por todos sus productos y/o servicios turísticos resultantes del uso sostenible y competitivo de sus atractivos (naturales, culturales, artificiales), elementos directos (servidores y/o empresarios turísticos) e indirectos (instituciones públicas e industrias conexas) del turismo, que se encuentren ubicados geográficamente en la zona (limites políticos y/o imaginarios de planificación) de la molécula turística, aclarando qué los corredores turísticos son parte activa de su oferta. De igual manera que en el modelo alternativo de funcionamiento del sistema 
turístico, las líneas que unan a los servidores y/o empresarios turísticos de la molécula, tienen que ser bien gruesas (información fluida) e incluso formando varios clústeres, que les permita mejorar sus productos y/o servicios por medio de la ejecución estrategias de desarrollo conjuntas, siempre con base en los gustos, preferencias necesidades, exigencias y tendencias de sus demandas turísticas, capacitándose de manera continua en temas pertinentes a las demandas de sus corrientes turísticas, para mantener el continuo dinamismo y competitividad en sus servicios y/o productos turísticos conjuntos.

Los corredores turísticos van a jugar un rol muy importante en el dinamismo de la molécula turística, porque serán quienes conecten las corrientes turísticas reales de los dos sistemas, generando el aumento del gasto y mejora de la experiencia turística.

La formación de moléculas turísticas, será la clave de la conformación de los enjambres de la industria del turismo mundial, explicando que estas moléculas pueden ser formadas con base en la pertinencia y compatibilidad de las modalidades de turismo conocidas y por conocer (turismo cultural, rural, de naturaleza, de playa, de negocios, de salud, alternativo, entre otros), dependiendo su formación además de la compatibilidad entre sí (similares gustos, preferencias, necesidades, exigencias y tendencias de sus corrientes turísticas), del estado de sus ambientes externos como: ambiente económico, ambiente político, ambiente sociocultural y ambiental, quienes regularan la temperatura interna de la atmósfera de la molécula turística sea esta adecuada o no para su funcionamiento eficiente relativo a la temperatura proporcionado por los ambientes externos.

\section{Supra Sistema Turístico}

Recordando que un sistema puede ser un destino turístico $\mathrm{x}$, un cantón, una provincia, una región, entre otros. Se explica que la molécula está formada por dos sistemas, y el supra sistema va a enlazar a dos o más moléculas turísticas pertinentes y compatibles entre sí, pero a diferencia de la formación de las moléculas, los supra sistemas van a mantener sus órganos rectores moleculares, estableciendo un enlazamiento por medio de convenios y tratados de cooperación intermolecular, con reuniones y flujo de información continuas que les permita la planeación, organización dirección y control conjunta, coordinada y armónica en todo el supra sistema turístico.

El supra sistema turístico estará compuesto por uno o más enlaces, entre dos o más órganos moleculares pertinentes y compatibles entre sí, significa que, sus productos y/o servicios que se ofertan, están acorde a los gustos, preferencias, necesidades, exigencias y tendencias de sus demandas turísticas, permitiendo a los turistas el disfrute a plenitud de un amplio 
abanico de productos y/o servicios que ellos esperaban tener, por lo que, su estadía se prolongará unos días más y su gasto aumentará tipo combustible para los servidores y/o empresarios de los motores del supra sistema turístico.

Gráfico 3. Suprasistema turístico de dos moléculas

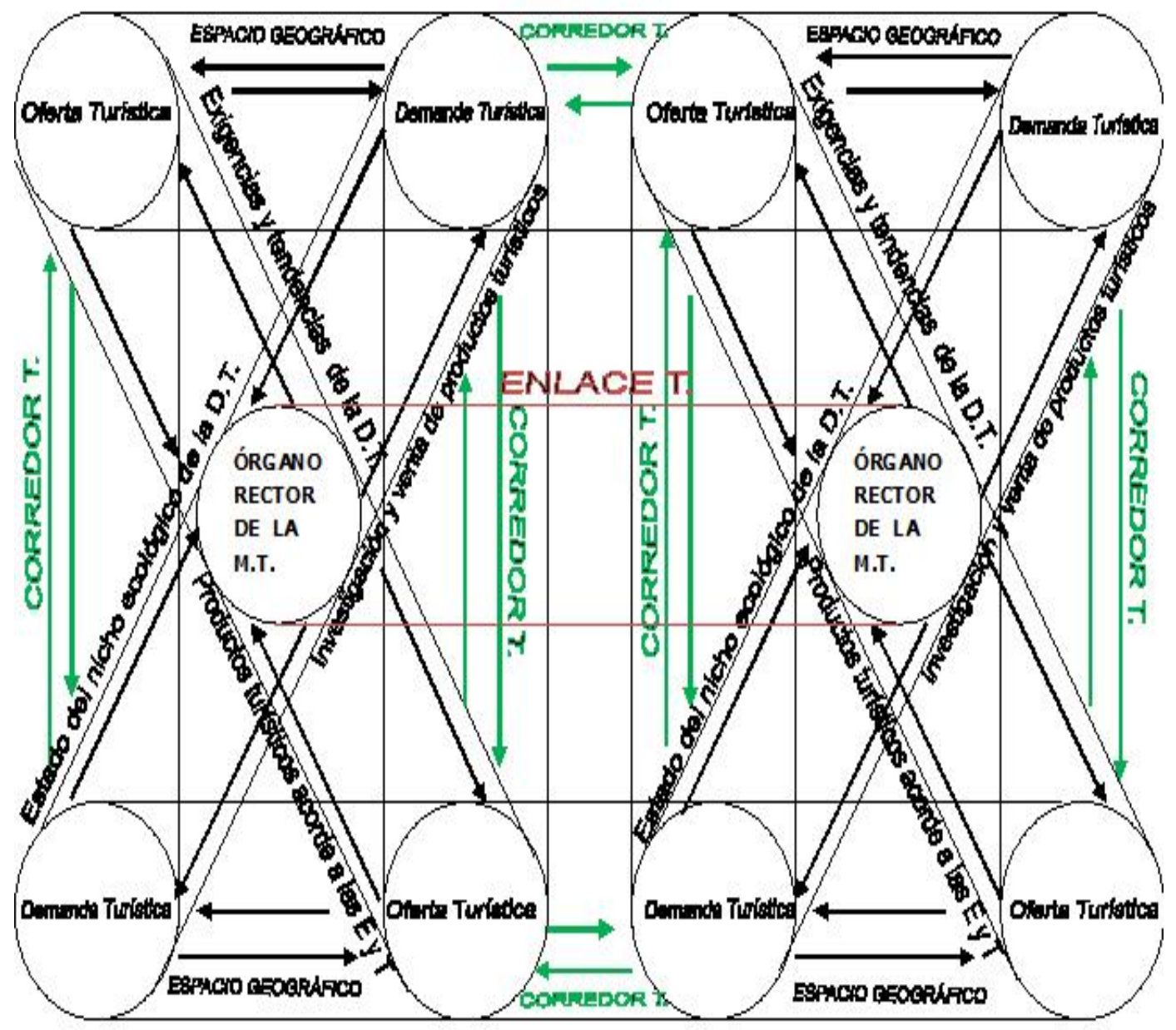

Fuente: Elaboración propia

Al momento de producirse el enlazamiento, deben crearse diversidad de corredores turísticos que conectarán la demanda con la oferta, dinamizando aún más los sistemas que lo conforman, permitiendo el desarrollo de los sectores o pueblos ubicados geográficamente en los corredores, por medio de la creación de empresas, micro empresas y/o emprendimientos que satisfagan las necesidades de alojamiento, alimentación, recreación, ocio y bienestar de sus corrientes turísticas. 


\section{Enjambre Turístico}

En 2015 la llegada de turistas a nivel mundial fue de 1.186 millones, que a su vez generaron 1.260.000 millones de dólares de ingresos en los destinos visitados, además en servicio de exportaciones de transporte internacional de pasajeros prestados o no residentes fue de 211.000 millones de dólares. El turismo internacional representa el 7\% de las exportaciones a nivel mundial de bienes y servicios, y como categoría mundial de exportación, ocupa el tercer puesto, tan solo por detrás de combustibles y de productos químicos, y por delante de alimentación y de la industria de automoción (OMT, 2016).

Estos datos muestran la magnitud de la industria turística a nivel mundial, la teoría que se desarrolla en el presente ensayo busca efectivizar aún más esta industria, con un enfoque sistémico-mecánico de desarrollo endógeno, desde los destinos turísticos hasta los enjambres de la industria del turismo mundial. Para ello es preciso comprender que un enjambre va a representar muchos destinos y/o sistemas turísticos entrelazados entre sí con la finalidad de satisfacer a plenitud los gustos, preferencias, necesidades, exigencias, tendencias de sus corrientes turísticas, que a su vez los enjambres pueden interconectarse entre sí, dando forma a la estructura de la industria del turismo mundial, generando mega espacios geográficos y mega corredores turísticos trabajados desde la atmosfera, hidrosfera y litosfera de nustro planeta.

El enjambre de la industria turística está formado por dos o más supra sistemas turísticos pertinentes y compatibles entre sí. En el gráfico 4, se interconectan ocho sistemas (destinos turísticos), generando cuatro enlaces turísticos entre los órganos rectores moleculares que conforman el enjambre; responsables de su planeación, organización, dirección y control, teniendo como su principal función la de investigar y monitorear el comportamiento, necesidades y tendencias de su multi-demanda turística, vender sus productos y/o servicios e incidir en el nicho ecológico de su multi-demanda turística potencial. 
Gráfico 4. Enjambre turístico compuesto de dos supra sistemas turísticos

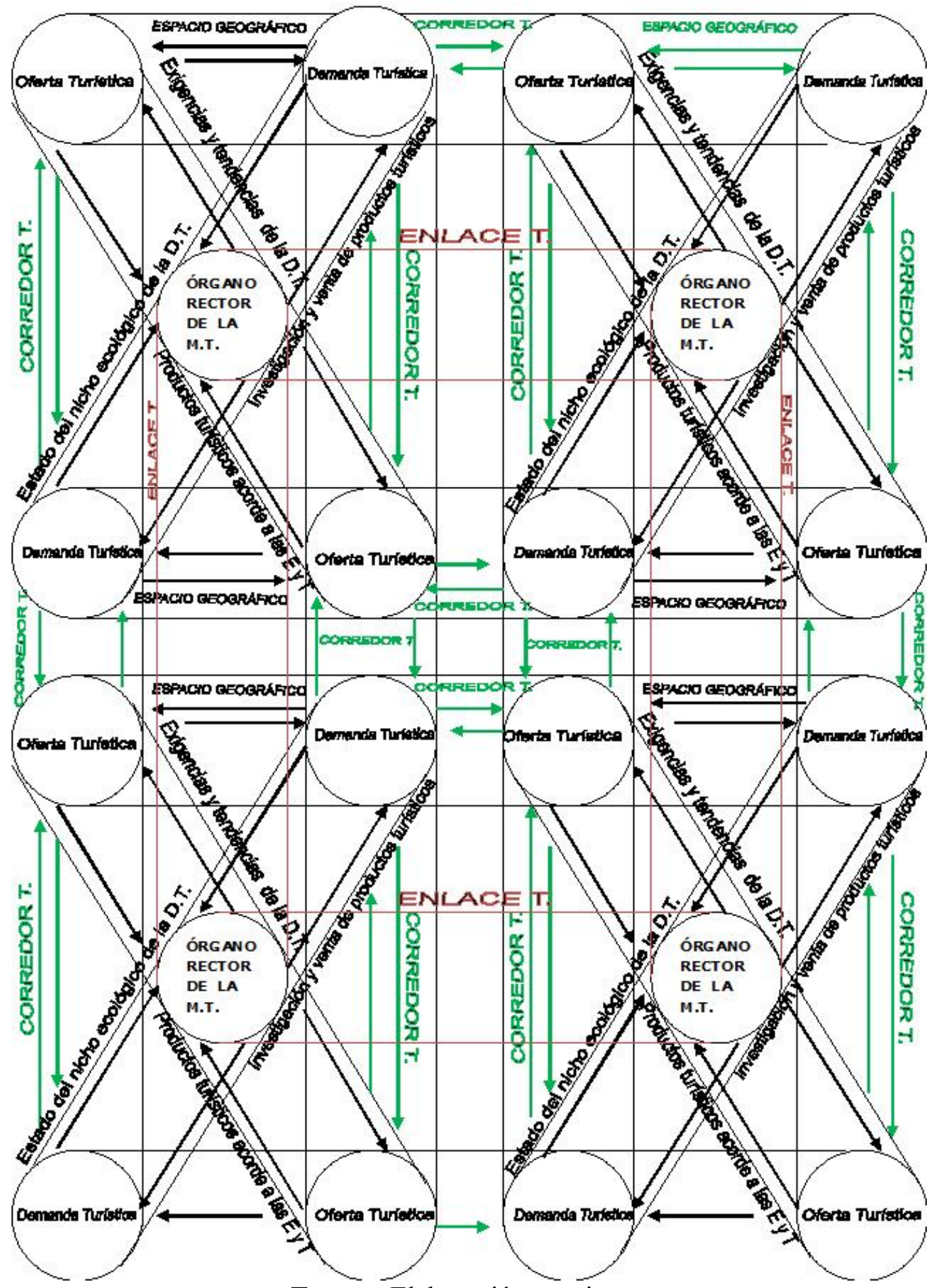

Fuente: Elaboración propia 
En el enjambre de la figura 4 se observan doce corredores turísticos que conectan a las corrientes turísticas de las ocho demandas, con los productos y/o servicios turísticos de sus ocho ofertas, generando la formación de súper productos y/o servicios turísticos, despertando una mega dinámica interna en toda la oferta del enjambre, permitiendo la creación de cientos de emprendimientos, micro y macro empresas que girarán en torno a los gustos, preferencias, necesidades, exigencias y tendencias de sus demandas turísticas, produciendo una gran cadena de valor que va ha reactivar las economías de todas las poblaciones implicadas directa o indirectamente en la oferta, espacio geográfico y corredores del enjambre turístico.

\section{Conclusion}

Se comprende claramente que no se puede observar al turismo como una actividad de componentes separados, aislados o sin una conexión mecánica desde la demanda hacia la oferta, esperando que estos se encuentren al azar o por intermedio de los operadores del mercado únicamente, ya qué, la función principal de ellos no es la de planeación, organización, dirección y control del sistema turístico, si no la de rentabilidad de su organización.

En el presente ensayo teórico estableció como unidad base de la industria del turismo mundial al sistema o destino turístico y explicó que al unir dos sistemas se obtiene una molécula turística, al enlazar dos o más moléculas se obtiene un supra sistema turístico, al entrelazar dos o más supra sistemas se obtiene un enjambre turístico y que al interconectar dos o más enjambres se obtendrá la estructura del turismo mundial.

La unión de los sistemas turísticos tendrá lugar, solo sí, los productos y/o servicios que oferten son compatibles con las necesidades, exigencias y tendencias de sus corrientes turísticas, caso contrario no se podrán formar las moléculas turísticas, supra sistemas turísticos, ni enjambres turísticos, teniendo presente que un enjambre es el resultado más complejo de destinos turísticos compatibles, que podrían interconectarse con otros tipos (modalidades de turismo) de enjambres pertinentes y compatibles entre sí, formando la estructura del turismo mundial.

\section{References:}

1. Abarca, M. A. (2017). Propuesta de un modelo alternativo de funcionamiento del sistema turístico. European Scientific Journal, 355.

2. Boullón, R. C. (2006). Planificación del Espacio Turístico. México: Trillas.

3. Carabias, J., \& Meave, V. C.-S. (2009). Ecología y Medio Ambiente en el siglo XXI. Mexico: Pearson Edicación. 
4. Cerro, M. M. (2009). ¿Moléculas sin esqueleto?: La oportunidad perfecta para revisar el concepto de estructura molecular. Educación química, Vol.20.

5. Muñoz, M. A. (2008). Inteligencia de enjambres: sociedades para la solución de problemas (una revisión). REVISTA INGENIERÍA E INVESTIGACIÓN , 120.

6. OMT (2016). Panorama OMT del turismo internacional. España: OMT.

7. Porter, M. E. (2003). Ser Competitivo Nuevas aportaciones y conclusiones. Barcelona-España: Deusto.

8. SANCHO, A. (1998). Introducción al Turismo. Organización Mundial de Turismo.

9. Torrejón, A. (2004). Glosario de terminos turísticos. Patagonia: Universidad Nacional de la Patagonia. 